\title{
A Compact High-Gain Coplanar Waveguide-Fed Antenna for Military RADAR Applications
}

\author{
Zaheer Ahmed Dayo, ${ }^{1}$ Qunsheng Cao $\left(\mathbb{D}^{1},{ }^{1}\right.$ Yi Wang, ${ }^{1}$ Sandeep Pirbhulal, \\ and Ali Hassan Sodhro ${ }^{3,4}$ \\ ${ }^{1}$ College of Electronic and Information Engineering, Nanjing University of Aeronautics and Astronautics, Nanjing 211106, China \\ ${ }^{2}$ Department of Information Security and Communication Technology, Norwegian University of Science and Technology, \\ 2815 Gjøvik, Norway \\ ${ }^{3}$ Computer and Information Science Department, Linkoping University, Linkoping, SE-58183, Sweden \\ ${ }^{4}$ Shenzhen Institutes of Advanced Technology, Chinese Academy of Sciences, Shenzhen (SIAT, CAS), Shenzhen, \\ Guangdong 518000, China
}

Correspondence should be addressed to Qunsheng Cao; qunsheng@nuaa.edu.cn

Received 17 February 2020; Revised 9 May 2020; Accepted 29 June 2020; Published 20 August 2020

Academic Editor: Mohammod Ali

Copyright (c) 2020 Zaheer Ahmed Dayo et al. This is an open access article distributed under the Creative Commons Attribution License, which permits unrestricted use, distribution, and reproduction in any medium, provided the original work is properly cited.

\begin{abstract}
This paper presents a new design of a compact, high-gain coplanar waveguide-fed antenna and proposes a multielement approach to attain enhanced characteristics. The proposed method overcomes the simulation and geometrical complexity and achieves optimal performance features. The antenna prototype is carefully designed, and simulation results have been analyzed. The proposed antenna was fabricated on a new WangLing TP-2 laminate with dimensions $(0.195 \lambda \times 0.163 \lambda \times 0.0052 \lambda)$ at the lowest resonance of $9.78 \mathrm{GHz}$. The results have been tested and experimentally verified. The antenna model achieved excellent performance including a peak realized gain better than $9.0 \mathrm{dBi}$, optimal radiation efficiency better than $87.6 \%$ over the operating band, and a good relative bandwidth of $11.48 \%$ at $10 \mathrm{~dB}$ return loss. Symmetrical stable far-field radiation pattern in orthogonal planes and strong distribution of current are observed. Moreover, a comparative analysis with state-of-the-artwork is presented. The measured and simulation result shows a good agreement. The high-performance antenna results reveal that the proposed model is a good contender of military airborne, land, and naval radar applications.
\end{abstract}

\section{Introduction}

The immense technological advancement in the wireless communication systems has switched focus to the development of compact, high gain, and radiation efficient antennas. Such antenna systems can be useful for various wireless communication applications including radar (radio detection and ranging), satellite, intercommunication, and navigational system [1].

Federal communication commission (FCC) under the third generation partnership project (3GPP) has allocated frequency ranges for different wireless communication applications. For instance, military airborne, land, and naval radars operate in $X$ band $8-12 \mathrm{GHz}, \mathrm{ISM}$, and wireless fidelity (WiFi) on $2.4 \mathrm{GHz}$ frequency band spectrum, and worldwide interoperability over microwave access (WiMAX) operates on a
$3.5-5.8 \mathrm{GHz}$ frequency range $[2,3]$. Therefore, it is essential to develop the high-performance antennas which can be utilized with an efficient wireless communication system, particularly for airborne, land, and naval radar applications. The conventional compact planar antennas (CPA) have low gain, limited radiation efficiency, and narrow bandwidth (BW) performance [4]. So, to improve CPA performance, studies have used different techniques.

In past studies, researchers tried to enhance the key performance parameters of the CPA by incorporating the various approaches [5-8]. Besides, several designs based on different shapes of slots [9-12], radiators [13-16], and ground plane $[17,18]$ have been proposed to attain the substantial peak realized gain, good radiation efficiency, and acceptable impedance BW along with perfect matching 
performance. The investigated antennas have complex designs and analyzed results were optimal with a trade-off between the BW, peak gain, radiation efficiency, and compact dimensions. The wideband bowtie dielectric resonator antenna was realized on Rogers TM10i and obtained a peak gain of $8 \mathrm{dBi}$ [19]. Another study on the bowtie antenna applied the complex structure of the artificial magnetic conductor ground plane and obtained the peak gain near $8 \mathrm{dBi}[20]$. Xu et al. proposed two antenna models [21]. They achieved the peak realized gain $5.1-5.5 \mathrm{dBi}$ and the radiation efficiency $71.5-77.2 \%$. Huang et al. proposed a multilayer high-gain antenna [22]. Their designed antenna obtained peak realized gain of $8.0-9.0 \mathrm{dBi}$ and $70-80 \%$ radiation efficiency. Li et al. suggested a method to achieve a high gain of $7 \mathrm{dBi}$ with larger dimensions of $22 \times 22 \mathrm{~cm}^{2}$ [23]. Iqbal et al. proposed a design with additional features to filter out the multiple bands and obtained the peak realized gain $3.4-4.6 \mathrm{dBi}[24]$.

Tawk et al. [25]; presented the bowtie antenna and obtained the maximum gain of $4.5 \mathrm{dBi}$. Sun et al. [26] have been proposed the new structure of the antenna with moderate gain performance of $1.7-5.8 \mathrm{dBi}$. Jalilvand et al. presented and investigated antenna based on a new 3D microwave tomography approach [27]. Mansoul et al. presented a compact antenna with $8 \times 3 \mathrm{~cm}^{2}$ space and obtained the enhanced peak gain performance of $4.5-5.8 \mathrm{dBi}$ [28]. Wu et al. [29] reported work on the slotted bowtie antenna with compact size $\left(6 \times 10 \mathrm{~cm}^{2}\right)$ and achieved a fair gain performance of $3.75 \mathrm{dBi}, 3.56 \mathrm{dBi}$, and $3.93 \mathrm{dBi}$. A new design of the bowtie slot antenna was investigated by Sallam et al. [30]. The antenna was realized on an $8 \times 6 \mathrm{~cm}^{2}$ compact size substrate and obtained the maximum gain of $6.3 \mathrm{dBi}$. Moreover, the wideband antenna using the altered T-shaped slot to the antenna was reported by Park et al. [31]. The proposed antenna has the dimensions of $15 \times 15 \mathrm{~cm}^{2}$ and obtained a high gain of 7.5-9 dBi.

Recently, several new approaches have been employed to improve the gain of compact antennas. Khalili et al. merged the traditional concept of bowtie antenna design with new metamaterial technology [32]. The antenna exhibited a peak realized gain of $10.21 \mathrm{dBi}$. The Fabry-Perot and slot antenna were reported in $[33,34]$. The authors achieve a high gain by employing the concept of loaded superstrate and increase the number of radiators with a $3 \mathrm{D}$ printed approach. The authors in [35] investigated the antenna array with complex methodology and obtained the gain higher than $8 \mathrm{dBi}$. It is worthy noted that the results analyzed and explained in [25-31] the researchers have not paid attention to the radiation efficiency of the antennas; also, the suggested methods were complex. However, the proposed antenna presented in this paper employed an alternative method that outperforms the maximum gain, radiation efficiency, and compact dimensions in comparison with most of the previously reported work.

Likewise, many other studies also improved the gain and efficiency of antenna systems using various techniques. However, such techniques were complex and time-taking. Therefore, we propose a novel method that enhances the gain and efficiency of an antenna. The employed method differs from other techniques, which generally altered radiation patch and added slots in the ground plane. Our multielement method applies to the simple geometry of the single bowtie arm radiator. The method consists of rectangular open-circuit stubs loaded extended ground plane (EGP) and circular disc-shaped stubs engraved on the upper left and right edge of the bowtie arm patch. Compared to previous work, our proposed method is a simpler one to achieve high gain and optimum radiation efficiency. The proposed approach is validated by applying the loaded stubs step by step to the proposed antenna lattice. It is verified that the antenna design structure using the EGP and extended bowtie arm patch is an effective and efficient way to attain the high gain, optimal radiation efficiency, and good impedance BW.

For the simulation and design of an intended radiator, a 3D electromagnetic high-frequency structure simulator (HFSS) virtual design prototyping research and development (R\&D) software is employed. As such, this study contributes to the academic research as follows: firstly, it designs and fabricates an antenna with miniaturized dimensions of $0.195 \lambda \times 0.163 \lambda \times 0.0052 \lambda$ on a new substrate material (WangLing TP-2); it presents a framework and optimal numerical results of the designed antenna, and it provides a comparative analysis with an existing state-ofthe-artwork.

The remainder of the manuscript proceeds as Section 2 illustrates the proposed approach for designed antenna and analyses of simulated results; Section 3 offers experimentally verified results; Section 4 elucidates comparative analysis; and Section 5 explains the conclusion of the study.

\section{The Proposed Approach for Antenna Design}

This section mainly focuses on the antenna framework design and analyses of simulation results. The cross-sectional view of the proposed compact, high gain, and radiation efficient antenna along with the fabricated sample are depicted in Figures 1(a) and 1(b). The simple design of the antenna composed of bowtie arm triangular-shaped radiator and ground plane fed by a standard $50 \Omega$ CPW feed line as elucidated in Figure 1(a). An subminiature-A (SMA) connector is properly modeled to excite the voltage and currents across the structure of the antenna. The proposed model of an antenna is engraved on the new substrate material WangLing TP-2 having values of dielectric constant $\varepsilon_{\mathrm{r}}=10.2$ and loss tangent $\tan \delta=0.001$. Two isosceles triangles are decreased in width toward the feeding line center and merged to form a single bowtie arm patch. The feed line width is partly responsible for reducing the fluctuations in input impedance $\left(Z_{0}\right)$ across the operational frequency. The partial ground plane with compact dimensions of $2.8 \times 2.13 \mathrm{~cm}^{2}$ is imprinted on the upper side of substrate. Further, two symmetrical open-circuit rectangular stubs with compact dimensions of $1.4 \times 1.0 \mathrm{~cm}^{2}$ are engraved on the upper left and right side of the metallic ground plane.

Likewise, the radiating structure of the antenna contains additional loaded rectangular stubs with miniature dimensions of $2.9 \times 0.3 \mathrm{~cm}^{2}$ and hence form an extended 


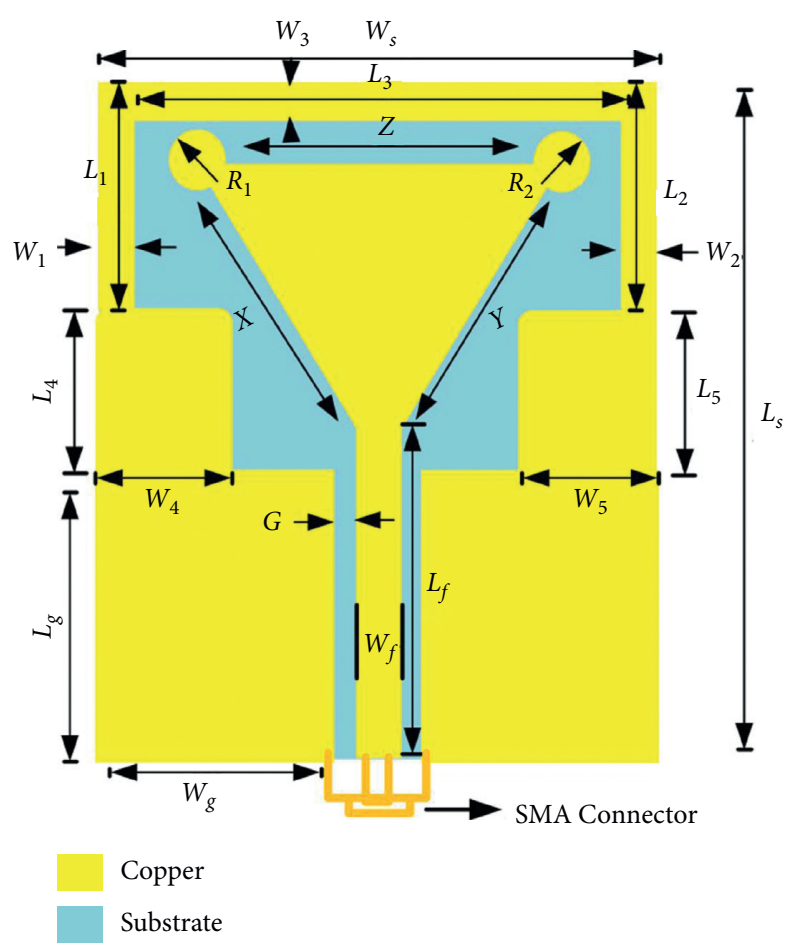

(a)

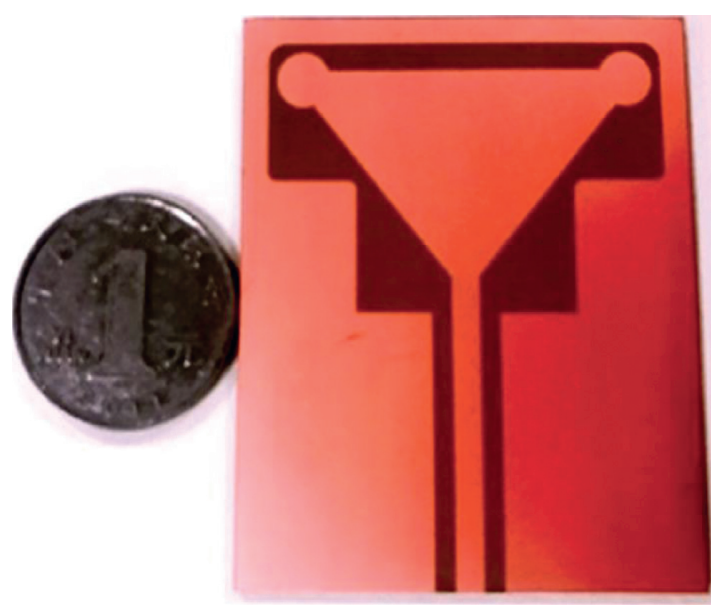

(b)

FIgURE 1: The geometrical structure of proposed antenna. (a) The designed antenna model with loaded circular disc-shaped stubs and modified ground plane. (b) The fabricated prototype of antenna with one Chinese yuan coin.

ground plane (EGP). This enhancement in the metallic ground plane is realized with loaded open-circuit rectangular stubs. The main purpose of this step-by-step alteration in the antenna structure is to tune resonances and attain the matching performance. Finally, two open-circuit circular disc-shaped loaded stubs etched on the upper right and left edge of the bowtie arm to form the proposed antenna prototype as displayed in Figure 1(a). The designed antenna is tuned by selecting the optimum values of important five variables, such as the width of the radiator $(Y / Z)$, length of the radiator $(X)$, the length, and width of a substrate $\left(L_{s} / W_{s}\right)$. Table 1 offers the utilized variables and their optimized values used in the designed antenna.

Figure 2 illustrates the return loss $\left(S_{11}\right)$ performance of the proposed antenna design structure. We notice that the proposed antenna achieves the broad BW of $9.78-10.97 \mathrm{GHz}$ at $10 \mathrm{~dB}$ return loss, which constitutes relative impedance $\mathrm{BW}$ of $11.48 \%$. Additionally, two resonances centered at $9.9 \mathrm{GHz}$ and $10.8 \mathrm{GHz}$ are observed across the operational frequency band. Also, the proposed antenna impedance bandwidth is increased by $37.8 \%$ as compared to [21]. The proposed antenna dimensions are very compact and decreased by $74.2,82.24$, 93.8 , and $86.6 \%$ as compared to recently reported work $[21-23,31]$.

Figure 3(a) shows the developed prototype simulation result of peak realized gain. The proposed model of antenna exhibited the maximum gain of $10.15 \mathrm{dBi}$ at $10.07 \mathrm{GHz}$ resonance. Also, the antenna structure attains a high gain of $9.18 \mathrm{dBi}$ and $8.1 \mathrm{dBi}$ over the operable frequency band $(9.78-10.97 \mathrm{GHz})$. The peak realized gain results reported in the literature have shown a decrement of 55.6 and $42.8 \%[25,26]$ and $61.2,37.9$, and $11.3 \%$ [29-31] in results as compared to the proposed highperformance antenna simulated results. Figure $3(\mathrm{~b}) \mathrm{de}-$ lineates the associated numerical result of radiation efficiency over the specified frequency. One can observe that the proposed antenna model achieves an excellent performance of $99.8 \%$ at $10.23 \mathrm{GHz}$ resonance. The antenna attains an efficiency of $96.7-98.6 \%$ across the operational band $(9.78-10.97 \mathrm{GHz})$. The radiation efficiency results presented in the literature have shown the decrement of 18.37 and $20 \%[21,22]$ as compared to the proposed antenna results.

It is important to investigate the concentration of current along the surface of antenna. This study demonstrates the current flow mechanism across the proposed structure. Figure 4(a) shows a simulation result of surface current distribution (Jsurf) at $9.9 \mathrm{GHz}$. A strong current density along the quarter length CPW feed line, bowtie arm radiator, and open-circuit rectangular stub loaded metallic ground plane is observed. Figure 4(b) illustrates the current distribution at $10.8 \mathrm{GHz}$. One can analyze that high current intensity is concentrated along with the structure of the proposed antenna.

\section{Experimental Verified Results}

This section covers the analyses of numerical and experimental verified outcomes of the return loss $(\mathrm{dB})$, maximum 
TABle 1: Defined variables along with improved values $(\mathrm{cm})$.

\begin{tabular}{lccccccccccccc}
\hline Variable name & $W_{s}$ & $L_{s}$ & $h_{s}$ & $L_{g}$ & $W_{g}$ & $L_{f}$ & $W_{5}$ & $W_{2}$ & $W_{3}$ & $L_{5}$ & $Y$ & $Z$ \\
\hline Optimized value $(\mathrm{cm})$ & 5.0 & 6.0 & 0.16 & 2.8 & 2.13 & 0.32 & 1.0 & 0.3 & 0.3 & 1.4 & 2.22 & 4.0 \\
\hline Variable name & $W_{f}$ & $L_{1}$ & $W_{1}$ & $L_{3}$ & $L_{4}$ & $R_{1}$ & $L_{2}$ & $W_{4}$ & $R_{2}$ & $X$ & $G$ & $T o C$ \\
\hline Optimized value $(\mathrm{cm})$ & 0.3 & 2.9 & 0.3 & 5.0 & 1.4 & 0.3 & 2.9 & 1.0 & 0.3 & 2.22 & 0.22 & 0.0035 \\
\hline
\end{tabular}

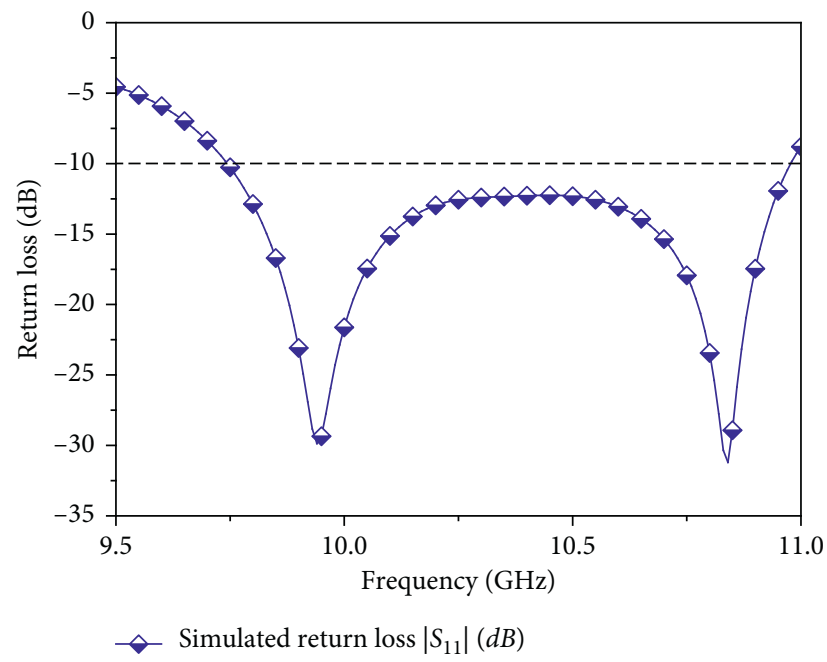

FIGURE 2: The return loss performance of developed prototype across the frequency span.

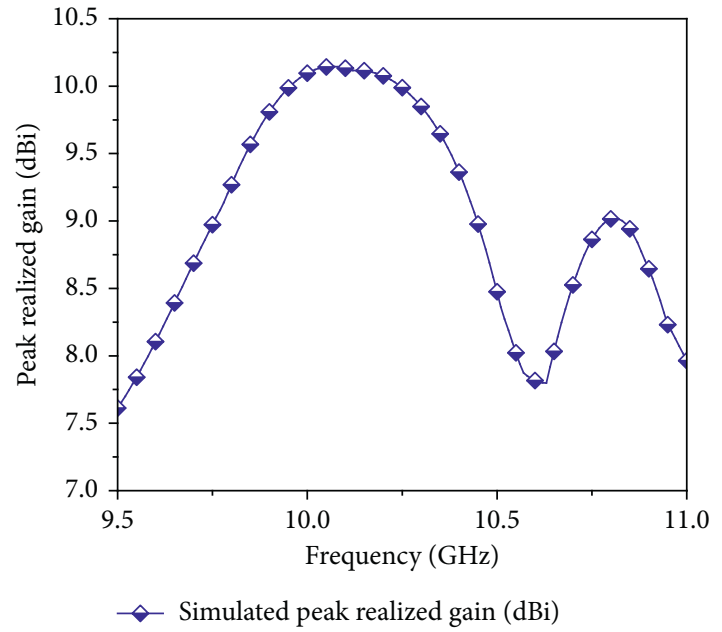

(a)

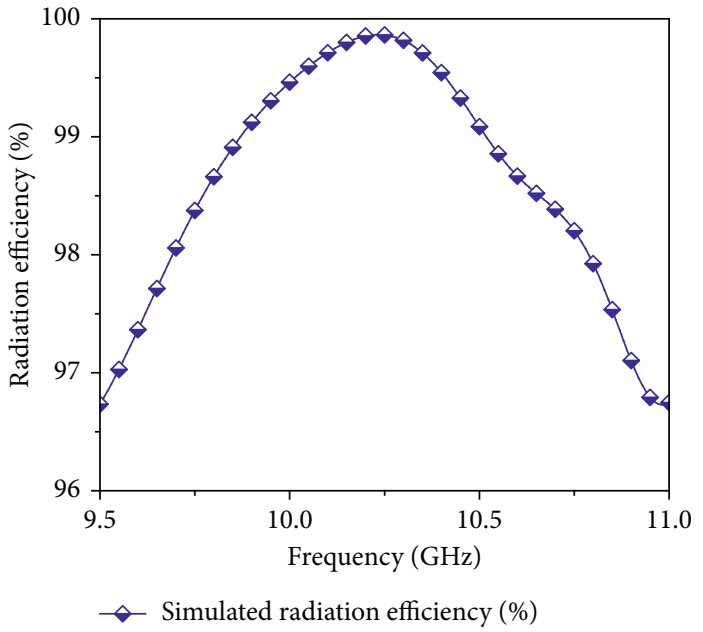

(b)

Figure 3: Simulated results. (a) Peak realized gain vs. operable frequency. (b) Radiation efficiency vs. operable frequency.

gain $(\mathrm{dBi})$, radiation efficiency $(\%)$, and far-field (2D) normalized radiation patterns.

3.1. Return Loss $(d B)$. Return loss $\left(S_{11}\right)$ of the manufactured antenna was quantified with a calibrated Agilent keysight vector network analyzer (VNA) PNA-XN5224 A. The fabricated prototype was conterminous to a port of VNA. The simulated and tested results are plotted in Figure 5 as observed from Figure 5; the simulated result (blue curve) has two resonances centered at $9.9 \mathrm{GHz}$ and $10.8 \mathrm{GHz}$. However, the measured results (red curve) also have two resonances centered at $9.8 \mathrm{GHz}$ and 10.9 GHz with a slight shift in frequency. Similarly, in the middle of the frequency band $(10.25-10.5 \mathrm{GHz})$, mismatching is observed in comparison to the simulation results. A slight deviation in measured results is observed mainly because of assembly error and experimental setup tolerances. Besides, during the simulation phase an SMA connector with input impedance of $50 \Omega$ (which possesses the minimal losses) was modeled to excite the antenna. However, the fabricated model of an antenna is fed with the practically available metallic SMA connector which includes some losses due to improper soldering and creates 

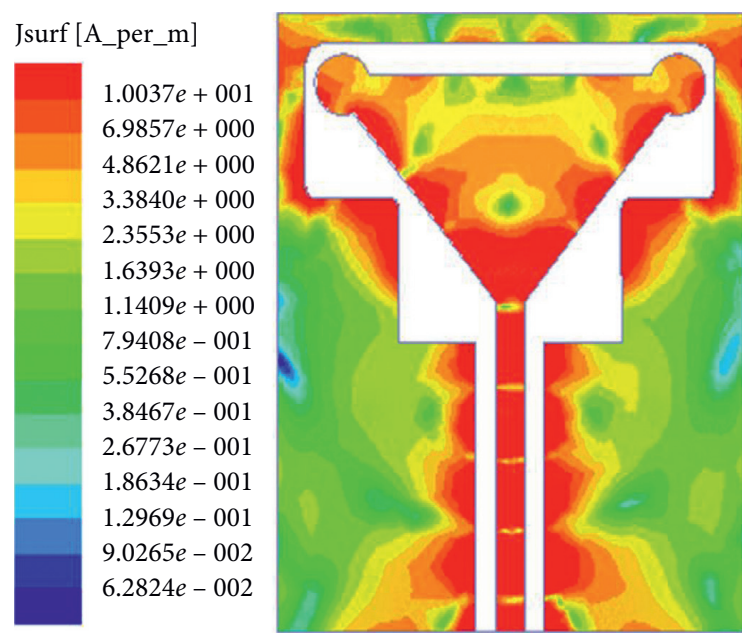

(a)

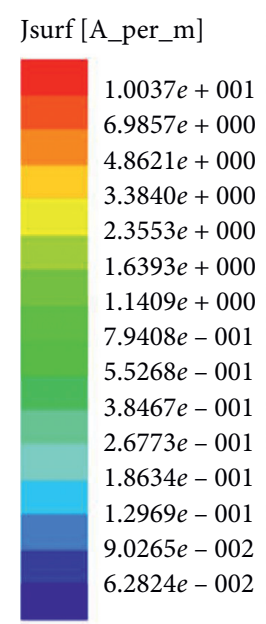

FIGURE 4: Surface current distribution. (a) @first resonance $9.9 \mathrm{GHz}$. (b) @second resonance $10.8 \mathrm{GHz}$.

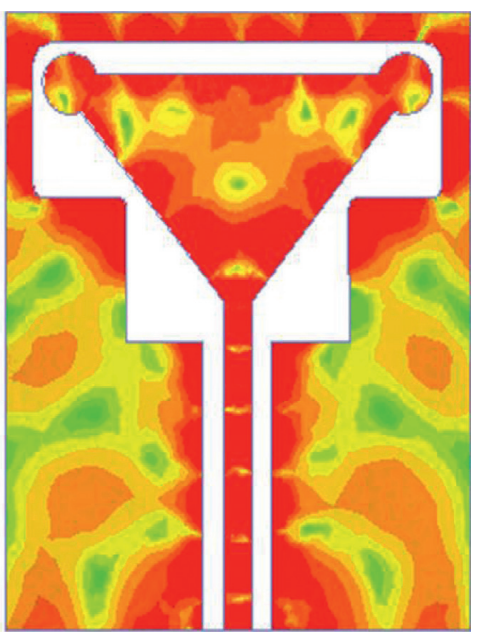

(b)

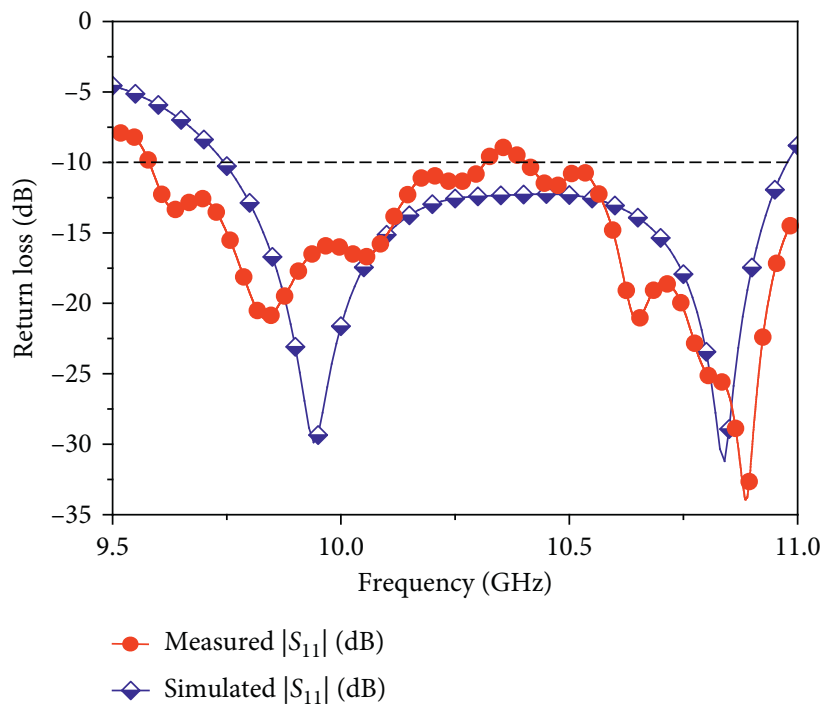

FIgURE 5: Tested and simulated return loss $(\mathrm{dB})$ across the operable frequency range.

parasitic inductance and capacitance losses which may lead to a discrepancy among the tested and simulated results. Moreover, this inaccuracy in results can be controlled by utilizing efficient substrate, high precision feeding connector, and good quality cables. Also, this small error in the measured results ensures the realization of the fabricated prototype.

3.2. Peak Realized Gain (dBi) and Radiation Efficiency (\%). The peak realized gain of a fabricated prototype was calculated by employing the standard Friis transmission formula approach. The value of gain is obtained using the following equation [36]:

$$
\left|S_{21}\right|^{2}=\left(1-\left|S_{11}\right|^{2}\right)\left(1-\left|S_{22}\right|^{2}\right) G_{T} G_{R}\left(\frac{c}{4 \pi R f}\right),
$$

where $S_{11}$ and $S_{22}$ are the reflection coefficients of feed antenna and antenna under test (AUT). Also, $G_{T}$ and $G_{R}$ are gain of the feed antenna and AUT [37]. $S_{21}$ is the insertion loss, denoting the power ratio at port 2 when feeding to port 1. The antenna is placed at a certain distance $R$ on the other side at a particular frequency $f$. Considering the above condition, two identical horn antennas with a known gain are placed in the line of sight (LOS) transmission as depicted in Figure 6(a). Likewise, an AUT (the sample of the antenna) is located at a certain distance under the same circumstances as delineated in Figures 6(b) and 6(c). Two physical samples were linked up to the transmitting and receiving ports of the network analyzer. The measurements were performed inside the anechoic chamber at a fixed distance (which fulfills the requirements of far-field transmission) of $4 \mathrm{~m}$ and $1 \mathrm{~m}$ high above the ground. Figure 7 delineates the graphical representation of overall measurement setup.

The tested and simulated peak realized gain of an antenna over the operable frequency range are illustrated and compared in Figures 8 (a) and $8(\mathrm{~b})$. It can be clearly 


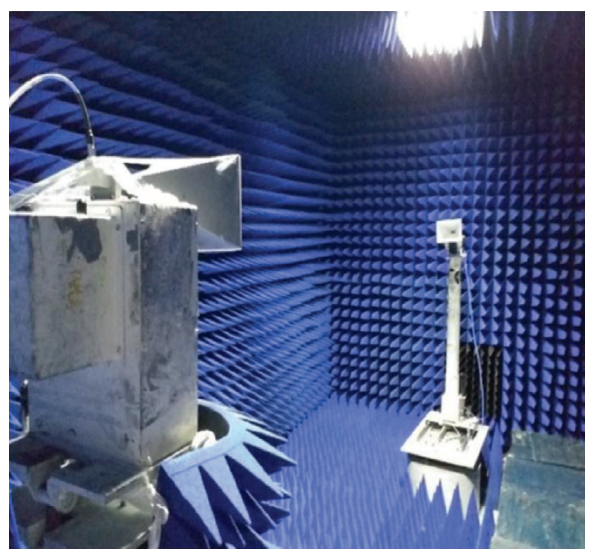

(a)

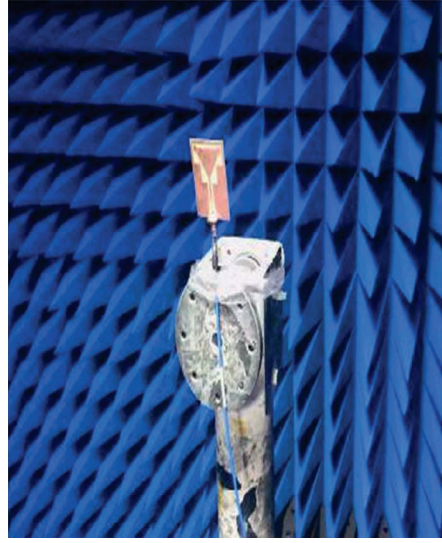

(b)

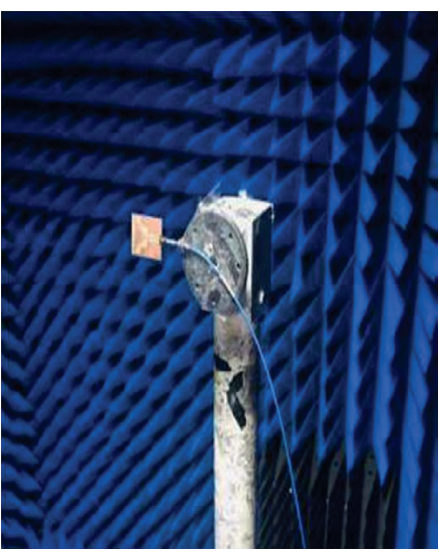

(c)

Figure 6: Photograph of tested antenna inside the chamber room. (a) The placement of identical horn antennas. (b, c) Fabricated prototype (AUT) placement on the azimuth rotator.

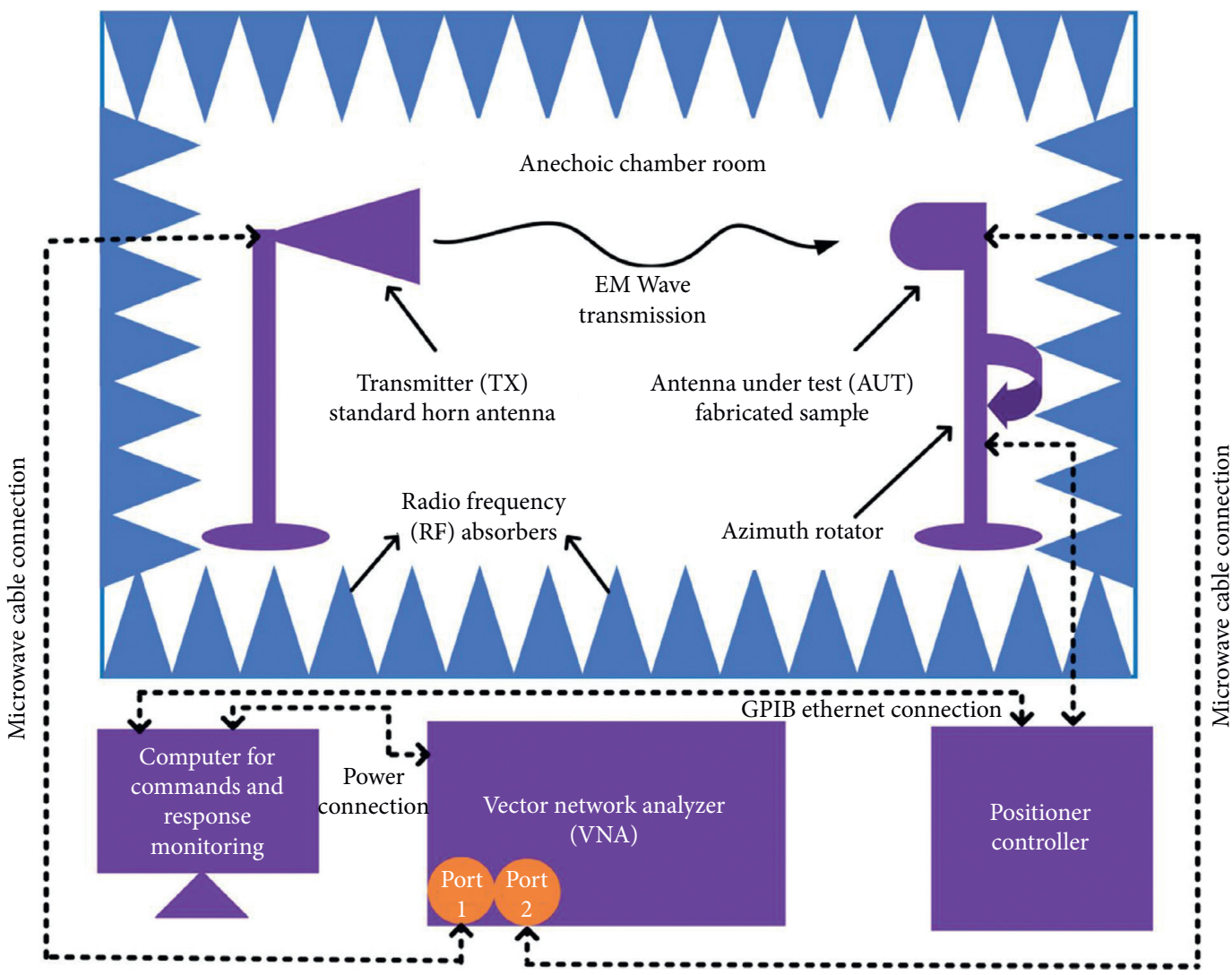

FIGURE 7: Graphical representation of overall measurement setup.

seen that the optimal gain of $10.15 \mathrm{dBi}$ (simulated) and $9 \mathrm{dBi}$ (measured) is observed at $10.07 \mathrm{GHz}$ and $10.09 \mathrm{GHz}$. Likewise, the minimum gain of $7.6 \mathrm{dBi}$ (simulated) and $7.1 \mathrm{dBi}$ (measured) is observed at $9.5 \mathrm{GHz}$. The calculated and simulation results are acquiescent and show the discrepancy of $1.15 \mathrm{dBi}$.

The radiation efficiency is a paramount parameter of the antenna which is defined as the ratio of radiated and accepted power. A simple, precise, and expeditious approach predicated on the directivity/gain information is employed to compute the efficiency of the fabricated archetype [38]. The measured efficiency is extracted from the following equation:

$$
\eta_{m}=\frac{G_{m}}{D_{s}}
$$

where $\eta_{m}$ and $G_{m}$ denote the measured efficiency and gain associated with fabricated prototype and $D_{s}$ represents the simulated directivity related to designed prototype. 


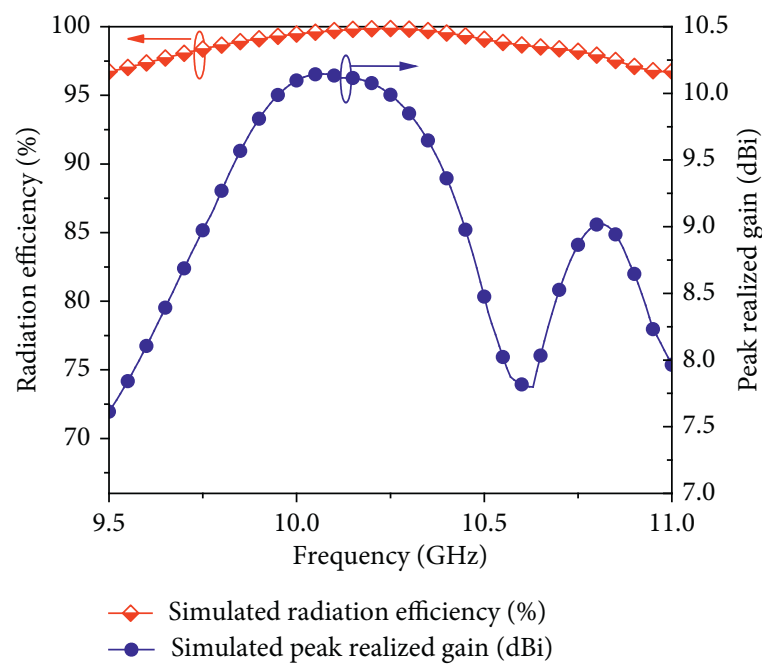

(a)

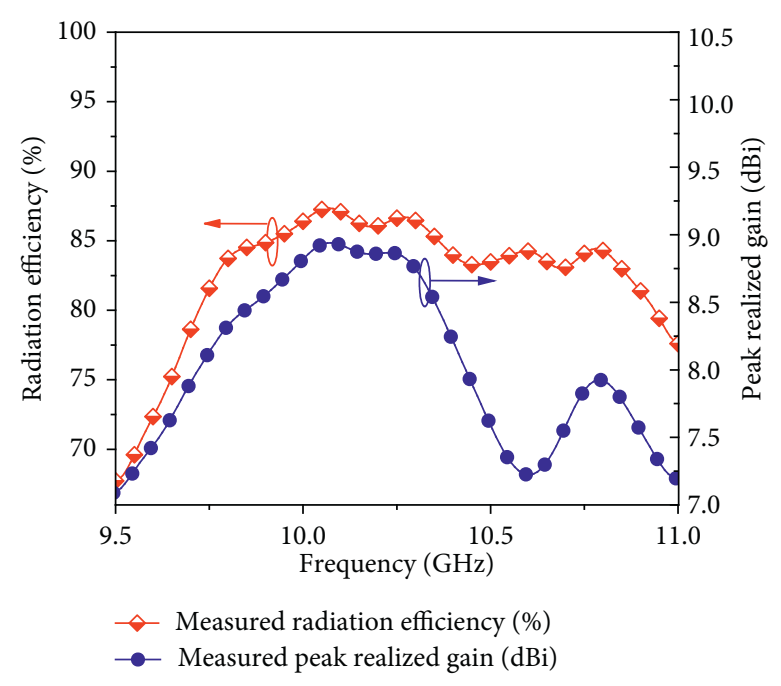

(b)

FIGURE 8: Radiation efficiency and peak realized gain over the operable frequency span (GHz). (a) Designed model. (b) Fabricated prototype.

Figures 8(a) and 8(b) show and compare the simulated and calculated radiation efficiency results of an antenna. The maximum efficiency of $99.8 \%$ (simulated) and $87.6 \%$ (measured) is realized at $10.23 \mathrm{GHz}$ and $10.06 \mathrm{GHz}$. Similarly, the minimum efficiency of $96.7 \%$ (simulated) and $66 \%$ (measured) is achieved at $9.5 \mathrm{GHz}$. The tested and simulated results are verified and show an acceptable deviation in the results.

3.3. Co-Polar and Cross-Polar Patterns. The co-polar and cross-polar two-dimensional (2D) patterns in standardplanes were measured inside the chamber room under farfield condition. The standard horn antenna was connected with a cable to the transmission signal anchorage of a VNA along with a tunable signal generator, whereas the fabricated sample of the antenna was kept fixed on a positioner, which acts as a far-field receiver at a $4 \mathrm{~m}$ distance as shown graphically in Figure 6. The positioner is rotated around $360^{\circ}$ to measure the radiation patterns in orthogonal planes, elevation (E-plane $\left(\phi=0^{\circ}\right)$ ), and azimuth (H-plane $\left.\left(\phi=90^{\circ}\right)\right)$, respectively.

Figures 9(a) and 9(b) provide the far-field two-dimensional (2D) normalized radiation pattern in orthogonal planes at $9.9 \mathrm{GHz}$. It is evident from Figure 9(a) that the antenna exhibits the omnidirectional radiation pattern in the elevation plane. Likewise, the measured results in the same plane are stable and symmetrical and show higher directivity around $200^{\circ}$ and $300^{\circ}$ as compared to simulated results. Figure 9(b) shows the antenna patterns in H-plane. The result shows that the antenna radiates equally in all directions. Moreover, the normalized radiation patterns in orthogonal planes at $10.8 \mathrm{GHz}$ are displayed in Figures 10(a) and 10(b). It is observed from Figure 10(a) that the radiating element exhibits the stable end-fire radiation pattern at a $90^{\circ}$ beam angle and maneuvering in the E-plane. Also, it can be noticed from Figure 10(b) that the proposed antenna radiated omnidirectionally in the azimuth plane.
In fact, the compact antennas have a good polarization level particularly in $\mathrm{H}$-plane caused by the dominant $\mathrm{TM}_{10}$ mode. As can be observed from Figures 9 and 10, the crosspolarization level is less than $-25 \mathrm{~dB}$. It is worthy to note that the X-polar level increases at certain points due to the excitation of $\mathrm{TM}_{02}$ mode. Also, the discrepancy in measured results is observed owing to the fact while the antenna rotation particularly in H-plane; the metallic surface of the antenna could not be covered by radio absorbing material (RAM) and power meter sensitivity in both standard planes.

Furthermore, it is noticed that in both principle planes the cross-polarization is lower than co-polarization owing to a conviction that the co-polarization level must be higher than the cross-polarization level especially for compact antennas. The proposed antenna has proven the above facts and figures about the radiation pattern performance. Hence, it has been confirmed that the proposed antenna received the maximum power in co-polar orientation and received less power in cross-polar orientation.

\section{Comparison Analysis}

The proposed model of antenna exhibits excellent performance results of peak realized gain and efficiency with miniaturized dimensions. A comparative analysis of the antenna key features with state-of-the-artwork is demarcated in Table 2. The high-gain and radiation efficient antennas were investigated in $[21,22]$ which occupied an ample space. In $[23,31]$, the proposed antenna achieved only high gain with ample space. Besides, it is noted that, in the presented work in $[23,31]$, the authors have not investigated the radiation efficiency of the antennas. The methods employed in the reported works were complex and timeconsuming. In this study, an alternative multielement approach is applied and excellent results are achieved as compared to most of the presented works. Moreover, with the deep analysis and owing to the trade-off among the antenna key features of the presented and analyzed results 


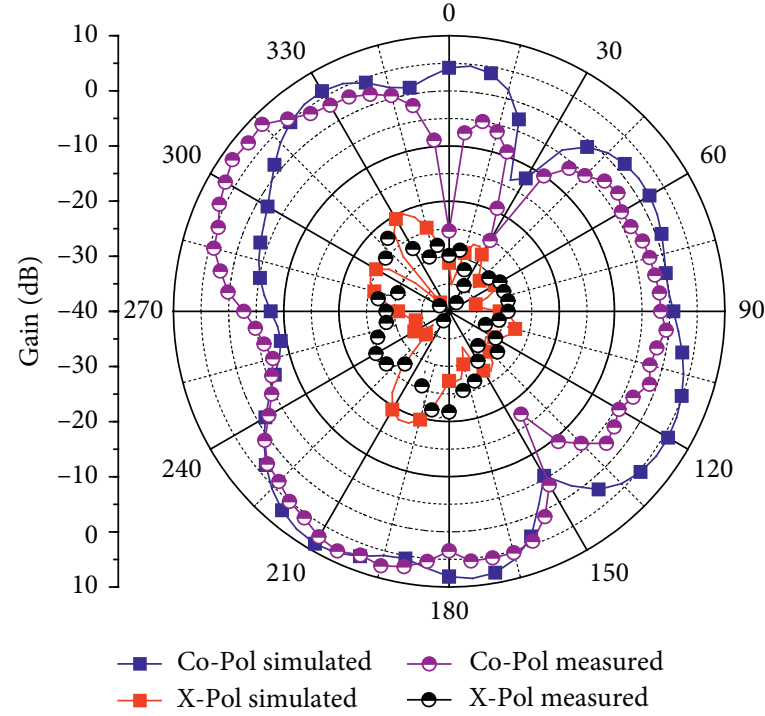

(a)

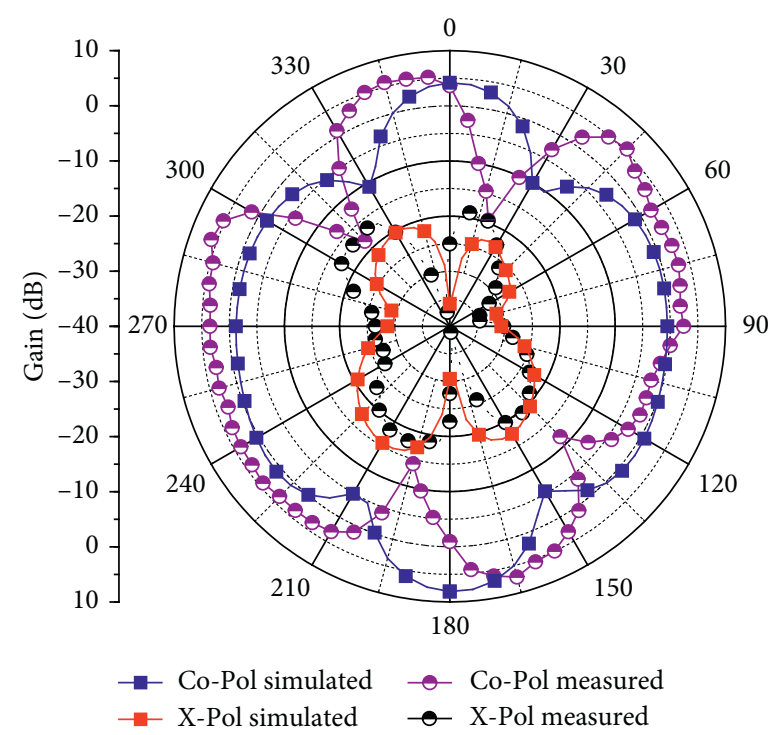

(b)

FIGURE 9: Simulated and tested normalized patterns. (a) E-Plane (XoZ) Co-X polarization at 9.9 GHz. (b) H-plane (YoZ) Co-X polarization at $9.9 \mathrm{GHz}$.

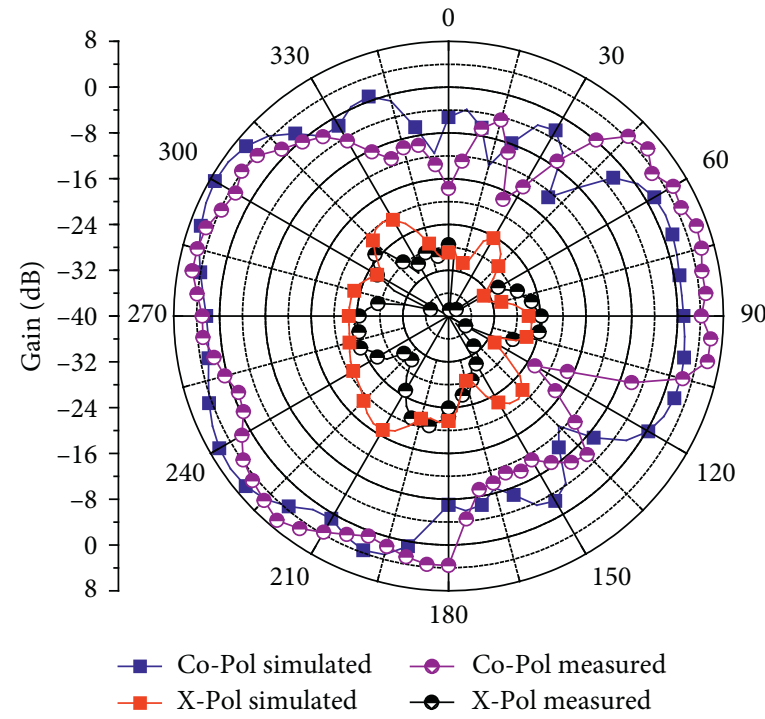

(a)

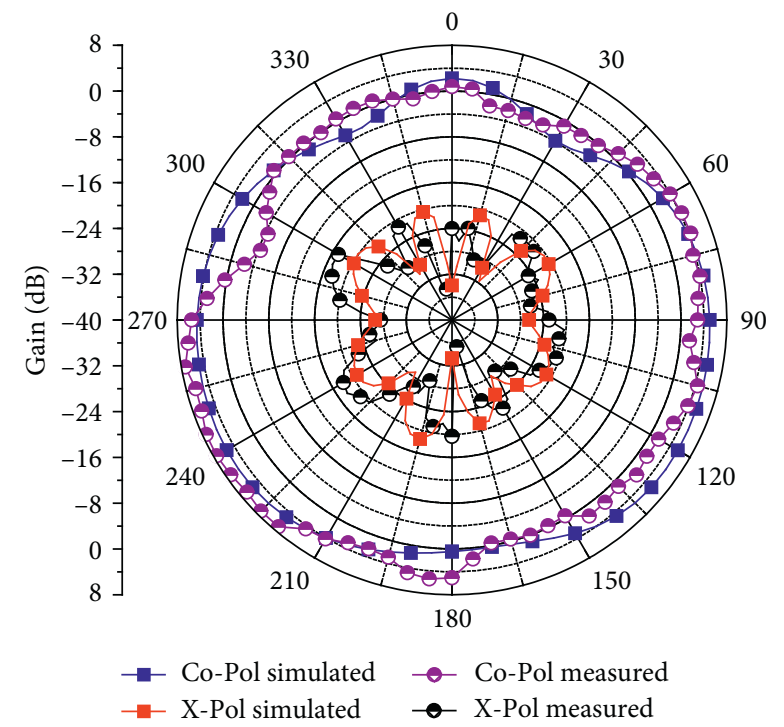

(b)

Figure 10: Simulated and tested normalized patterns. (a) E-plane (XoZ) Co-X polarization at 10.8 GHz. (b) H-plane (YoZ) Co-X polarization at $10.8 \mathrm{GHz}$.

TABLE 2: Antenna key features of compared results.

\begin{tabular}{|c|c|c|c|c|c|}
\hline Year and ref. & $\begin{array}{c}\text { Antenna dimensions } \\
\left(\mathrm{cm}^{3}\right)\end{array}$ & $\begin{array}{c}\text { Overall occupied } \\
\text { space }\left(\mathrm{cm}^{2}\right)\end{array}$ & $\begin{array}{l}\text { Max. gain }(\mathrm{dBi}) \\
\text { (measured) }\end{array}$ & $\begin{array}{c}\text { Max. radiation efficiency } \\
(\%) \text { (measured) }\end{array}$ & $\begin{array}{l}\text { Utilized antenna design } \\
\text { approach } \\
\end{array}$ \\
\hline 2020 (this work) & $6 \times 5 \times 0.16$ & 30 & 9.0 & 87.6 & $\begin{array}{c}\text { Single layer } \\
\text { multielement approach }\end{array}$ \\
\hline 2019 [21] & $15.5 \times 7.5 \times 0.08$ & 116.25 & 5.1 & 71.5 & $\begin{array}{l}\text { Folded dual IFA on a } \\
\text { metallic RIM }\end{array}$ \\
\hline 2019 [22] & $\begin{array}{l}\text { Lower } 10 \times 10 \times 0.16 \\
\text { Upper } 13 \times 13 \times 0.16\end{array}$ & $\begin{array}{l}100 \\
169\end{array}$ & 8.0 & 70 & Multilayer hybrid mode \\
\hline 2019 [23] & $22 \times 22 \times 0.15$ & 484 & $\sim 7$ & Unspecified (US) & $\begin{array}{l}\text { Embedded slot and } \\
\text { stubs }\end{array}$ \\
\hline $2018[31]$ & $15 \times 15 \times 0.16$ & 225 & 7.5 & US & Modified T-shaped slot \\
\hline
\end{tabular}


reported in the open literature, it is estimated that the performance analysis results may not be better than the obtained results of the antenna presented in this paper. Therefore, it is concluded that the utilized approach in the designed antenna can exhibit high gain, optimum radiation efficiency performance, good impedance BW, stable far-field patterns, and strong flow of current across the radiator space.

\section{Conclusion}

A new structural design of a compact, high-gain CPW-fed antenna has been presented. The model comprised of a metallic single bowtie arm radiator, ground plane, and standard $50 \Omega \mathrm{CPW}$ feeding line. The antenna elements were engraved on the new WangLing TP-2 thick substrate material. The novel multielement approach was employed to realize optimal performance features. The proposed structure possessed a compact size of $0.195 \lambda \times 0.163 \lambda \times 0.0052 \lambda$ at the lowest resonance of $9.78 \mathrm{GHz}$. The antenna model has been fabricated and results are verified. The proposed archetype exhibited a good relative BW of $11.48 \%$, an optimal realized gain better than $9.0 \mathrm{dBi}$, and excellent radiation efficiency better than $87.6 \%$. The symmetrical stable radiation patterns and strong density of current were observed. Moreover, the proposed antenna key characteristics have been compared with state-of-the-artwork. The antenna exhibited the optimal results of realized gain and radiation efficiency with a great advantage of small size. An acceptable agreement among the simulated and tested results has been observed that makes it a competitive choice for military airborne, land, and naval radar applications.

\section{Data Availability}

The data used to support the findings of this study are included within the article.

\section{Conflicts of Interest}

The authors declare that there are no conflicts of interest regarding the publication of this manuscript.

\section{Acknowledgments}

The authors Zaheer Ahmed Dayo, Qunsheng Cao, and Yi Wang gratefully acknowledge the support from the National Natural Science Foundation of China under Grant no. 61871219.

\section{References}

[1] L. Xu, L. Li, and W. Zhang, "Study and design of broadband bow-tie slot antenna fed with asymmetric CPW," IEEE Transactions on Antennas and Propagation, vol. 63, no. 2, pp. 760-765, 2015.

[2] T. S. Rappaport, Y. Xing, G. R. MacCartney, A. F. Molisch, E. Mellios, and J. Zhang, "Overview of millimeter wave communications for fifth-generation (5G) wireless networks-with a focus on propagation models," IEEE Transactions on Antennas and Propagation, vol. 65, no. 12, pp. 6213-6230, 2017.
[3] Z. A. Dayo, Q. Cao, Y. Wang, S. Ur Rahman, and P. Soothar, "A compact broadband antenna for civil and military wireless communication applications," International Journal of Advanced Computer Science, vol. 10, no. 9, pp. 39-44, 2019.

[4] C. A. Balanis, Antenna Theory: Analysis and Design, 3rd edition, 2009.

[5] A. A. Eldek, A. Z. Elsherbeni, and C. E. Smith, "Wideband bow-tie slot antenna with tuning stubs," in Proceedings of the IEEE National Radar Conference, pp. 583-588, New York, NY, USA, August 2004.

[6] F. Wu and K. M. Luk, "Wideband high-gain open resonator antenna using a spherically modified, second-order cavity," IEEE Transactions on Antennas and Propagation, vol. 65, no. 4, pp. 2112-2116, 2017.

[7] J.-H. Chen, C.-K. Yang, C.-Y. Cheng, C.-C. Yu, and C.-H. Hsu, "Gain enhancement of a compact 2.4-GHz meander antenna using inductive feed and capacitive load," Microwave and Optical Technology Letters, vol. 59, no. 10, pp. 2598-2604, 2017.

[8] X. Cai, W. Geyi, and H. Sun, "A printed dipole array with high gain and endfire radiation," IEEE Antennas and Wireless Propagation Letters, vol. 16, pp. 1512-1515, 2017.

[9] Y. X. Guo, K. M. Luk, K. F. Lee, and R. Chair, "A quarter-wave U-shaped patch antenna with two unequal arms for wideband and dual-frequency operation," IEEE Trans. Antennas Propag.vol. 50, no. 8, pp. 1082-1087, 2002.

[10] N. Farrokh-Heshmat, J. Nourinia, and C. Ghobadi, "Bandnotched ultra-wideband printed open-slot antenna using variable on-ground slits," Electronics Letters, vol. 45, no. 21, p. 1060, 2009.

[11] S. T. Fan, Y. Z. Yin, B. Lee, W. Hu, and X. Yang, "Bandwidth enhancement of a printed slot antenna with a pair of parasitic patches," IEEE Antennas and Wireless Propagation Letters, vol. 11, pp. 1230-1233, 2012.

[12] R. G. Pierce, A. J. Blanchard, and R. M. Henderson, "Broadband planar modified aperture bowtie antenna," IEEE Antennas and Wireless Propagation Letters, vol. 12, pp. 1432-1435, 2013.

[13] K. F. Tong, K. M. Luk, K. F. Lee, and R. Q. Lee, “A broad-band $£ 7$-slot rectangular patch antenna on a microwave substrate," IEEE Trans. Antennas Propag.vol. 48, no. 6, pp. 954-960, 2000.

[14] N. Ojaroudi and M. Ojaroudi, "A novel design of reconfigurable small monopole antenna with switchable band notch and multi-resonance functions for UWB applications," $M i$ crowave and Optical Technology Letters, vol. 55, no. 3, pp. 652-656, 2013.

[15] L. S. Solanki, S. Singh, and D. Singh, "Modified wideband bowtie antenna for WLAN and high speed data communication applications," Wireless Personal Communications, vol. 95, no. 3, pp. 2649-2663, 2017.

[16] H. N. Awl, Y. I. Abdulkarim, L. Deng, and M. Bakır, "Bandwidth improvement in bow-tie microstrip Antennas: the effect of applied sciences bandwidth improvement in bow-tie microstrip Antennas : the E ff ect of substrate type and design dimensions," Applied Science, vol. 10, pp. 2-14, 2020.

[17] S. Soltani, R. A. Sadeghzadeh, B. S. Virdee, L. Asadpor, and M. Naser-Moghadasi, "Improved band-notch technique for ultra-wideband antenna," Antennas and Propagation, vol. 4, no. 11, p. 1886, 2010.

[18] M. J. Chiang, T. F. Hung, J. Y. Sze, and S. S. Bor, "Miniaturized dual-band CPW-Fed annular slot antenna design with arcshaped tuning stub," IEEE Transactions on Antennas and Propagation, vol. 58, no. 11, pp. 3710-3715, 2010. 
[19] L. Z. Thamae and Z. Zhipeng Wu, "Broadband bowtie dielectric resonator antenna," IEEE Transactions on Antennas and Propagation, vol. 58, no. 11, pp. 3707-3710, 2010.

[20] X.-Y. Song, C. Yang, T. Zhang, Z.-H. Yan, and R. Lian, "Broadband and gain enhanced bowtie antenna with AMC ground," Progress In Electromagnetics Research Letters, vol. 61, pp. 25-30, 2016.

[21] Z. Xu, C. Ding, Q. Zhou, Y. Sun, and S. Huang, “A dual-band dual-antenna system with common-metal rim for smartphone applications," Electronics, vol. 8, no. 3, p. 348, 2019.

[22] F. Gary Zhang, "A patch/dipole hybrid-mode antenna for sub-6 GHz communication," Sensors, vol. 19, no. 1358, pp. 1-7, 2019.

[23] K. Li, T. Dong, and Z. Xia, "Wideband printed wide-slot antenna with fork-shaped stub," Electronics, vol. 8, no. 3, p. 347, 2019.

[24] A. Iqbal, A. Smida, N. Mallat, M. Islam, and S. Kim, "A compact UWB antenna with independently controllable notch bands," Sensors, vol. 19, no. 6, p. 1411, 2019.

[25] Y. Tawk, K. Y. Kabalan, A. El-Hajj, C. G. Christodoulou, and J. Costantine, "A simple multiband printed bowtie antenna," IEEE Antennas and Wireless Propagation Letters, vol. 7, pp. 557-560, 2008.

[26] J.-S. Sun, C.-K. Hu, and Y.-C. Lee, "A new broadband hybrid bow-tie antenna for wireless applications," Microwave and Optical Technology Letters, vol. 51, no. 8, pp. 1905-1908, 2009.

[27] T. Zwick, M. Jalilvand, J. Kowalewski, and X. Li, "Broadband miniaturised bow-tie antenna for 3D microwave tomography," Electronics Letters, vol. 50, no. 4, pp. 244-246, 2014.

[28] A. Mansoul and M. L. Seddiki, "Multiband reconfigurable Bowtie slot antenna using switchable slot extensions for WiFi, WiMAX, and WLAN applications," Microwave and Optical Technology Letters, vol. 60, no. 2, pp. 413-418, 2018.

[29] M.-T. Wu and M.-L. Chuang, "Multibroadband slotted bowtie monopole antenna," IEEE Antennas and Wireless Propagation Letters, vol. 14, pp. 887-890, 2015.

[30] M. O. Sallam, S. M. Kandil, V. Volski, G. A. E. Vandenbosch, and E. A. Soliman, "Wideband CPW-fed flexible bow-tie slot antenna for WLAN/WiMax systems," IEEE Transactions on Antennas and Propagation, vol. 65, no. 8, pp. 4274-4277, 2017.

[31] J. S. Park and H. K. Choi, "Design of a wideband bowtie antenna using a modified T-shaped slot," Microwave and Optical Technology Letters, vol. 60, no. 8, pp. 1979-1984, 2018.

[32] F. Khajeh-Khalili, M. Amin Honarvar, and A. Dadgarpour, "High-gain bow-tie antenna using array of two-sided planar metamaterial loading for $\mathrm{H}$-band applications," International Journal of RF and Microwave Computer-Aided Engineering, vol. 28, no. 7, pp. 1-7, 2018.

[33] Q. Chen, X. Chen, and K. Xu, "3-D printed Fabry-Pérot resonator antenna with paraboloid-shape superstrate for wide gain bandwidth," Applied Science, vol. 7, no. 11, 2017.

[34] K. K. So, K. M. Luk, C. H. Chan, and K. F. Chan, "3D printed high gain complementary dipole/slot antenna array," Applied Science, vol. 8, no. 8, 2018.

[35] S. S. Hesari and J. Bornemann, "Antipodal Vivaldi antenna arrays fed by substrate integrated waveguide right-angled power dividers," Applied Science, vol. 8, no. 12, 2018.

[36] M. Roudjane, M. Khalil, A. Miled, and Y. Messaddeq, "New generationwearable antenna based on multimaterial fiber forwireless communication and real-time breath detection," Photonics, vol. 5, no. 4, 2018.

[37] M. Z. Rafique, Q. Cao, and Z. Lian, "Accuracy improvement for antenna measurement in a noisy anechoic chamber using an artificial way," in Proceedings of the 2019 IEEE
International Conference on Computational Electromagnetics, Shanghai, China, March 2019.

[38] Y. Huang, "Radiation efficiency measurements of small antennas," Handbook of Antenna Technologies, vol. 3, pp. 2165-2189, 2016. 